\title{
Estimating the rate of plasmid transfer: an end-point method
}

\author{
L. Simonsen, ${ }^{1 *}$ D. M. Gordon, ${ }^{1}$ F. M. STEWART ${ }^{2}$ and B. R. LeVin ${ }^{1}$ \\ ${ }^{1}$ Department of Zoology, University of Massachusetts, Amherst, MA 01003, USA \\ ${ }^{2}$ Department of Mathematics, Brown University, Providence, RI 02912, USA
}

(Received 15 May 1990; revised 23 July 1990; accepted 25 July 1990)

\begin{abstract}
We describe a method for determining the rate parameter of conjugative plasmid transfer that is based on single estimates of donor, recipient and transconjugant densities and the growth rate in exponential phase of the mating culture. The formula for estimating the plasmid transfer rate, $\gamma$, was derived from a mathematical model describing cell growth and plasmid transfer in batch culture. Computer simulations were used to explore the sensitivity of this method to the realities of bacterial life, such as growth rate differences, plasmid segregation and transitory derepression of pilus synthesis. As predicted by the theory, mating experiments with the plasmid R1 in Escherichia coli $\mathrm{K} 12$ demonstrated that the estimate $\gamma$ is unaffected by cell density, donor:recipient ratio and mating time. Unlike previous techniques, our method allows us to investigate the effect of environmental factors on plasmid transfer rates when these factors also influence population growth rates. To illustrate this, we examined the effect of temperature on the rate of plasmid transfer.
\end{abstract}

\section{Introduction}

Information about the rate of plasmid transfer is critical if one wishes to address questions relating to the ecology and evolution of plasmids: for example, the spread of antibiotic resistance determinants or the risks associated with the release of genetically engineered microorganisms. A variety of different measures have been used to quantify plasmid transfer. Watanabe (1963) considered the relative number of transconjugants and plasmid-bearing cells observed over time. Curtiss $e t$ al. (1969) determined the ratio of transconjugants to donor cells, while Bale et al. (1987) reported the ratio of transconjugants to recipient cells. Anderson (1975) defined transfer ability as the minimum number of donors necessary to observe transfer in a fixed period of time. Each of these measures permits rough comparisons of plasmid transfer within a study. However, since these measures depend on factors such as cell density, mating time and donor : recipient ratios, it is difficult to compare fertility estimates among studies with different experimental protocols.

Thus, there is a need for a general measure of plasmid transfer that is independent of these factors, akin to the transmission parameter employed in models of infectious disease (Anderson \& May, 1978). This objective was achieved when Levin et al. (1979) described a procedure to estimate the rate constant of conjugative plasmid transfer, $\gamma$. However, their method has not been widely used, perhaps because it is time-consuming and inappropriate for measuring the relatively low transfer rates of most plasmids.

We present a method for determining the rate of plasmid transfer that overcomes the shortcomings of previous techniques. Our end-point method is based on a single estimate of the densities of donor, recipient and transconjugant populations and the exponential growth rate of the total population in batch mating cultures. From a mathematical model of plasmid transfer kinetics under batch culture conditions, we derive a formula for determining the rate of plasmid transfer, $\gamma$. We use computer simulations to explore the sensitivity of our estimate to realistic departures from the assumptions of the model. To demonstrate some of the properties of our estimate, we present results of batch culture mating experiments using the plasmid $\mathrm{R} 1$ in Escherichia coli hosts.

\section{Methods}

Plasmid transfer experiments. Variants of the $E$. coli $\mathrm{K} 12$ strain $\mathrm{CSH} 7$ (Miller, 1972) were used. The donor carried the IncFII plasmid Rl (Km Ap $\mathrm{Cm} \mathrm{Sm} \mathrm{Su}$ ), and a spontaneous nalidixic acid resistant mutant of CSH7 was selected and used as the recipient. With these strains, donors, recipients and transconjugants could be estimated by selective plating on TL plates (broth with tetrazolium and lactose) (Levin et al., 1979) with chloramphenicol $\left(25 \mu \mathrm{g} \mathrm{ml}^{-1}\right)$ and/or nalidixic acid $\left(20 \mu \mathrm{g} \mathrm{ml}^{-1}\right)$ added. The matings were done in $50 \mathrm{ml}$ Erlenmeyer flasks containing $10 \mathrm{ml}$ Luria broth (LB) or glucose-limited salt medium DM 
(Sambrook et al., 1989). The mating cultures were incubated at $37^{\circ} \mathrm{C}$ and shaken at 150 r.p.m. The exponential-phase population growth rates were estimated by measuring $\mathrm{OD}_{670}$. With the exception of the kinetics experiment, there were five flasks per treatment and the cultures were sampled at stationary phase. The standard errors on the estimates of the transfer rate parameter $\gamma$ were about $10 \%$ of the mean values. Where significance values are given, they are calculated using analysis of variance (AOV) of $\log _{10} \gamma$.

Computer simulations. The ordinary differential equations specifying the models were solved numerically using a fourth-order Runge-Kutta method implemented by the SOLVER package (Bence et al., 1986).

\section{Theory}

Levin et al. (1979) demonstrated that the kinetics of plasmid transfer in exponentially growing liquid cultures can be described by a simple mass-action model. The four basic assumptions of their model are: (1) matings occur among randomly distributed planktonic cells at a frequency proportional to the product of the densities of plasmid-bearing and plasmid-free cells, (2) there is no plasmid loss due to segregation, (3) newly formed transconjugants immediately transfer the plasmid and do so at the same rate as the original donors, (4) all clones grow at the same constant rate.

We modified their basic model so it now describes cell growth and plasmid transfer in a batch mating culture. The model considers the changes in the densities (cells $\mathrm{ml}^{-1}$ ) of donors, $D$, recipients, $R$, transconjugants, $T$, and the resource concentration, $C\left(\mu \mathrm{g} \mathrm{ml}^{-1}\right)$, with respect to time due to growth and plasmid transfer:

$$
\begin{aligned}
& \dot{R}=\psi(C) \cdot R-\gamma(C) \cdot R \cdot(D+T) \\
& \dot{D}=\psi(C) \cdot D \\
& \dot{T}=\psi(C) \cdot T+\gamma(C) \cdot R \cdot(D+T) \\
& \dot{C}=-\psi(C) \cdot(R+D+T) \cdot e
\end{aligned}
$$

where a $\operatorname{dot}(\cdot)$ denotes differentiation with respect to time, $\psi$ is the growth rate $\left(\mathrm{h}^{-1}\right), \gamma$ is the transfer rate parameter $\left(\mathrm{ml} \mathrm{cell}{ }^{-1} \mathrm{~h}^{-1}\right)$, and $e(\mu \mathrm{g})$ is the amount of resource required to produce a new cell. We assumed the rates of growth and plasmid transfer are Monod functions (Monod, 1949) of resource concentration, $C$, so that when resources are exhausted, growth and conjugation cease:

$$
\psi(C)=\psi_{\max } \cdot C /(Q+C), \gamma(C)=\gamma_{\max } \cdot C /(Q+C)
$$

where $Q$ is the half saturation constant $\left(\mu \mathrm{g} \mathrm{ml}^{-1}\right)$, and $\psi_{\max }$ and $\gamma_{\max }$ are the maximal rates of cell growth and plasmid transfer, respectively.

\section{Derivation of the equation for $\gamma$}

Let $N=R+D+T, Y=T / R$, and $S=D / N$. Take $N$ as the independent variable and use primes(') to indicate differentiation with respect to $N$. Since $C+e N$ is constant, we can regard $\psi$ and $\gamma$ as functions of $N$, although the exact function will depend upon initial conditions.

Let $\beta=\gamma / \psi$. Then:

$$
\begin{aligned}
& \dot{N}=\psi \cdot N \\
& R^{\prime}=\dot{R} / \dot{N}=[R-\beta \cdot R \cdot(D+T)] / N \\
& D^{\prime}=\dot{D} / \dot{N}=D / N \\
& T^{\prime}=\dot{T} / \dot{N}=[N+\beta \cdot R \cdot(D+T)] / N
\end{aligned}
$$

Hence

$$
\begin{aligned}
Y^{\prime} & =\frac{\left[R \cdot T^{\prime}-T \cdot R^{\prime}\right]}{R^{2}} \\
& =\frac{\beta}{N \cdot R^{2}}\left[R^{2} \cdot D+R^{2} \cdot T+T \cdot R \cdot D+T^{2} \cdot R\right] \\
& =\frac{\beta}{N \cdot R^{2}}\left[R^{2} \cdot D+R \cdot T \cdot N\right]=\beta \cdot[S+Y]
\end{aligned}
$$

and

$$
S^{\prime}=\left[N \cdot D^{\prime}-D\right] / N^{2}=0
$$

Since $\beta=\gamma / \psi=\gamma_{\max } / \psi_{\max }$ is constant, then

$$
\beta=\left[\ln \left(S+Y_{1}\right)-\ln \left(S+Y_{0}\right)\right] /\left[N_{1}-N_{0}\right]
$$

where the subscripts 0 and 1 denote the initial and final values of $Y$ and the total cell density $N$, respectively. When there are no transconjugants at the starting point $\left(Y_{0}=0\right)$, then

$$
\gamma / \psi=\ln \left(1+Y_{1} / S\right) /\left[N_{1}-N_{0}\right]
$$

and

$$
\gamma=\psi \ln \left(1+\frac{T}{R} \cdot \frac{N}{D}\right) \cdot \frac{1}{\left[N-N_{0}\right]}
$$

\section{The experimental protocol for estimating $\gamma$}

The protocol is based on simple batch mating cultures. Here, $R, D, T$ are the estimated cell densities (determined by selective plating) at the time of sampling (end-point), and the growth rate $\psi$ is calculated from as few as two determinations of optical density taken during the exponential phase of the mating culture, using the formula:

$$
\psi=\frac{\ln \left(\mathrm{OD}_{\mathrm{b}} / \mathrm{OD}_{\mathrm{a}}\right)}{t_{\mathrm{b}}-t_{\mathrm{a}}}
$$

where $t_{\mathrm{b}}$ and $t_{\mathrm{a}}$ are the times (h) at which $\mathrm{OD}_{\mathrm{b}}$ and $\mathrm{OD}_{\mathrm{a}}$ were obtained.

The cultures may be sampled at any time during exponential growth or stationary phase (provided there is no cell death or plasmid transfer after growth ceases), when the transconjugant population density is large 
enough to be detected. If the culture is sampled when $N \gg N_{0}$, then the initial population density need not be determined and it is only necessary to sample the mating culture, at the end-point.

This end-point estimate of the plasmid transfer rate parameter $\gamma$ approaches the maximal transfer rate, regardless of the time of sampling. This is because $\gamma$ and $\psi$ are likely to remain proportional to each other and vary little during exponential growth.

\section{Results}

\section{Exploring the sensitivity of the end-point method}

The assumptions underlying the model and the derivation of the equation for $\gamma$ are, of course, unrealistic simplifications. To explore the effect of other realistic complications on the accuracy of $\gamma$, we modified our model to incorporate the existence of a lag phase, plasmid segregation, growth rate differences and transitory derepression of sex pilus synthesis. The effect of a single complication is determined by comparing the estimated value of plasmid transfer $\gamma$ with the value of $\gamma$ obtained for the same set of parameters, but without the complication. This calculated reference value of $\gamma$ deviated less than $2 \%$ from the input maximal transfer rate, $\gamma_{\max }$. In our simulation experiments, we varied $\gamma_{\max }$ over a range which encompasses typically observed transfer rates under laboratory conditions. The stationary-phase cell densities were used to estimate $\gamma$. In all simulations the initial resource concentration was $750 \mu \mathrm{g}$ $\mathrm{ml}^{-1}, Q=4 \mu \mathrm{g} \mathrm{ml}^{-1}$ and $e=5 \times 10^{-7} \mu \mathrm{g}$.

The effect of lag phase. We examined the effect of lag phase by incorporating an initial period of predefined duration, where no cell growth occurred, but the plasmid transferred at its maximal rate. In reality, the plasmid transfer rate accelerates to its maximum during lag phase; therefore, we considered a 'worst-case scenario' in our simulations. The lag phase duration was varied from 0 to $6 \mathrm{~h}$ and the rate of plasmid transfer, $\gamma_{\max }$, from $1 \times 10^{-9}$ to $1 \times 10^{-15}$. Two sets of simulations were done: a high $\left(1 \times 10^{7}\right.$ cells ml $\left.{ }^{-1}\right)$ and a low $\left(1 \times 10^{3}\right.$ cells ml $\left.^{-1}\right)$ initial cell density. Even for high initial cell densities, less than a $1 \%$ difference between the estimated $\gamma$ and its expected value could be detected for any combination of lag phase duration and transfer rate $\gamma_{\text {max }}$.

Transitory derepression. Many plasmids are normally repressed with respect to conjugative pilus synthesis (Willetts, 1974). Upon transfer to a new host cell, the transfer operon of the plasmid is transitorily derepressed for a short time (Willetts, 1974; Lundquist \& Levin,
1986). We mimicked this effect in our model in the same manner as Lundquist \& Levin (1986). All newly formed transconjugants were assumed to transfer the plasmid at a faster rate (2-6 orders of magnitude) than the original donors, and the time that newly formed transconjugants were derepressed before they entered the repressed transconjugant population was varied from 0 to 6 cell generations.

The results of our simulation showed that transitory derepression results in an overestimation of $\gamma$; the error increased the longer the cells remain in the derepressed state (Table $1 a$ ). The magnitude of the error (less than twofold) is most dependent on the transfer rate in the derepressed state, while the repressed rate and the relative difference between repressed and derepressed rates has little effect. The transfer rate was overestimated by less than $40 \%$ in simulations where the derepressed rate was $1 \times 10^{-9}$, irrespective of the repressed rate $\left(1 \times 10^{-12}\right.$ or $\left.1 \times 10^{-15}\right)$, whereas no measurable error was obtained when the derepressed transfer rate was $1 \times 10^{-12}$ and the repressed transfer rate was $1 \times 10^{-15}$.

Growth rate differences. The basic model assumes the three cell populations grow at the same rate. In an extended model, we introduced different maximal growth rates for the three populations, and let these rates be the same Monod functions of resource concentration as in the basic model. First, we investigated the effect of differences in the growth rate of plasmid-bearing cells relative to the plasmid-free cells: $(a)$ in a situation where the plasmid was under positive selection $\left(\psi_{D}=\psi_{T}>\psi_{R}\right)$ and $(b)$ when there was a cost of plasmid carriage $\left(\psi_{D}=\psi_{T}<\psi_{R}\right)$. We assumed that the plasmid transfer rate was unaffected by the growth rate differences.

The simulations revealed that fitness effects are asymmetrical: the error in the estimated transfer rate is small $(<21 \%)$ when plasmid-free cells have a growth rate advantage, but when the plasmid-bearing cells have the advantage (Table $1 b$ ). The error on $\gamma$ is greater for lower rates of plasmid transfer. For example, when plasmid-bearing cells grow at twice the rate of the recipients and $\gamma_{\max }$ is $1 \times 10^{-9}, \gamma$ was overestimated by $35 \%$, while for a $\gamma_{\max }$ of $1 \times 10^{-12}$ the error was $64 \%$ (Table 1). Additional simulations (not shown) demonstrated that changing the initial donor and recipient densities from $1 \times 10^{6}$ to $1 \times 10^{3}$ cells $\mathrm{ml}^{-1}$ had little effect on the estimate of the transfer rate. However, initial densities of $1 \times 10^{8}$ cells $\mathrm{ml}^{-1}$ significantly improved the estimate $\gamma$.

In cases where donors and recipients are different strains or species, they are likely to have different growth rates. To investigate the effect of this complication, we performed simulations where the growth rate of the donor and recipient strains were different, but where 
Table 1. Computer simulations of the batch culture models: the effect of complications on the estimate of the plasmid transfer rate, $\gamma$

The results are presented as the percentage error on the estimate of $\gamma$, relative to the $\gamma$ obtained from the basic model for the same parameter values $(+$ when overestimated and - when underestimated). (a) Transitory derepression. The errors on the estimate of the repressed transfer rate, $\gamma_{1}$, are reported for different durations of transitory derepression and maximal transfer rates. The initial donor and recipient densities were $5 \times 10^{6} \mathrm{cells}^{-1}$ and $\psi_{\max }$ was $1.0 \mathrm{~h}^{-1}$. (b) Growth rate differences. From these simulations, $\gamma$ was calculated using the mating culture exponential growth rate $\psi$ estimated as $\ln \left(N_{3 \mathrm{~h}} / \mathrm{N}_{\text {initial }}\right) / 3$. Varying the absolute growth rates between $0.5<\psi<$ 8 had a slight effect on the estimate of $\gamma$. The reported values are the largest errors. The initial donor

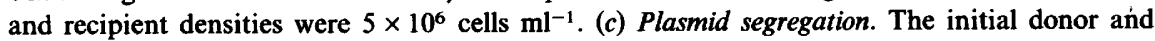
recipient densities were $1 \times 10^{3}$ cells $\mathrm{ml}^{-1}$ and $\psi_{\max }$ was $1.0 \mathrm{~h}^{-1}$.

\begin{tabular}{|c|c|c|c|c|c|}
\hline \multicolumn{6}{|c|}{ (a) Effect of transitory derepression } \\
\hline \multicolumn{2}{|c|}{ Maximal transfer rates } & \multicolumn{4}{|c|}{$\begin{array}{l}\text { Duration of derepression } \\
\text { (no. of generations) }\end{array}$} \\
\hline $\begin{array}{c}\text { Repressed } \\
\gamma_{1}\end{array}$ & $\begin{array}{c}\text { Derepressed } \\
\gamma_{2}\end{array}$ & $1 \cdot 0$ & $2 \cdot 0$ & $4 \cdot 0$ & $6 \cdot 0$ \\
\hline $\begin{array}{l}1 \times 10^{-12} \\
1 \times 10^{-15} \\
1 \times 10^{-15}\end{array}$ & $\begin{array}{l}1 \times 10^{-9} \\
1 \times 10^{-12} \\
1 \times 10^{-9}\end{array}$ & $\begin{array}{r}+18 \% \\
0 \% \\
+18 \%\end{array}$ & $\begin{array}{r}+26 \% \\
0 \% \\
+26 \%\end{array}$ & $\begin{array}{r}+34 \% \\
0 \% \\
+34 \%\end{array}$ & $\begin{array}{r}+38 \% \\
0 \% \\
+38 \%\end{array}$ \\
\hline
\end{tabular}

(b) Growth rate differences

Growth rate of plasmid-bearing cells/growth rate of plasmid-free cells

\begin{tabular}{cccccccccc}
\cline { 2 - 7 } & 0.1 & 0.5 & 0.8 & 0.9 & 1.0 & $1 \cdot 1$ & 1.25 & 2.0 & 10 \\
\hline $1 \times 10^{-9}$ & $-21 \%$ & $-13 \%$ & $-4 \%$ & $-1 \%$ & $0 \%$ & $+2 \%$ & $+4 \%$ & $+35 \%$ & $+105 \%$ \\
$1 \times 10^{-12}$ & $-21 \%$ & $-16 \%$ & $-8 \%$ & $-5 \%$ & $0 \%$ & $+5 \%$ & $+11 \%$ & $+64 \%$ & $+333 \%$ \\
$1 \times 10^{-15}$ & $-21 \%$ & $-16 \%$ & $-8 \%$ & $-5 \%$ & $0 \%$ & $+5 \%$ & $+11 \%$ & $+64 \%$ & $+335 \%$ \\
\hline
\end{tabular}

(c) Effect of plasmid segregation

Segregation rate $\left(\mathrm{h}^{-1}\right)$

\begin{tabular}{cccccc}
\cline { 2 - 5 }$\gamma_{\max }$ & 0.0 & 0.001 & 0.01 & 0.10 & 0.50 \\
\hline $1 \times 10^{-9}$ & $0 \%$ & $-0.3 \%$ & $-3 \%$ & $-21 \%$ & $-58 \%$ \\
$1 \times 10^{-10}$ & $0 \%$ & $0 \%$ & $-1 \%$ & $-8 \%$ & $-13 \%$ \\
$1 \times 10^{-11}$ & $0 \%$ & $0 \%$ & $0 \%$ & $-1 \%$ & $-1 \%$ \\
$1 \times 10^{-12}$ & $0 \%$ & $0 \%$ & $0 \%$ & $0 \%$ & $0 \%$ \\
\hline \hline
\end{tabular}

plasmid carriage had no impact on fitness $\left(\psi_{D}>\psi_{R}=\psi_{T}\right.$ or $\left.\psi_{D}<\psi_{R}=\psi_{T}\right)$. The pattern of underand overestimation and the magnitude of the error associated with the estimated transfer rate similar to those obtained in the first set of simulations (results not shown): when the transconjugants and recipients grow at twice the rate of the donors, $\gamma$ is overestimated by $62 \%$; and in the opposite case, $\gamma$ is underestimated by $16 \%$.

Segregation. We investigated the effect of plasmid loss due to segregation by assuming donors and transconjugants lost the plasmid at the same constant rate. Transconjugants that lost the plasmid returned to the recipient population and the donors that lost the plasmid entered a second recipient population (if these recipients re-acquire a plasmid, they return to the donor population). We varied the segregation rate from 0 to $0.5 \mathrm{~h}^{-1}$; the maximum rate corresponds to $30 \%$ of the donors losing their plasmid per generation at a growth rate of $1.0 \mathrm{~h}^{-1}$ (42 min generation time).

For simulations where $\gamma_{\max }$ was $10^{-11}$ or lower, less than $1 \%$ error on the estimated transfer rates were obtained, regardless of the segregation rate. For a high plasmid transfer rate $\left(1 \times 10^{-9}\right)$, the error grew for increasing segregation rates; thus for a $0.5 \mathrm{~h}^{-1}$ segregation rate $\gamma$ was underestimated by $58 \%$ (Table $1 c$ ). Changing the initial cell density to $1 \times 10^{3}$ cells ml ${ }^{-1}$ had little effect on the estimate of $\gamma$, despite the fact that the transconjugant density at stationary phase varied for different initial densities. 


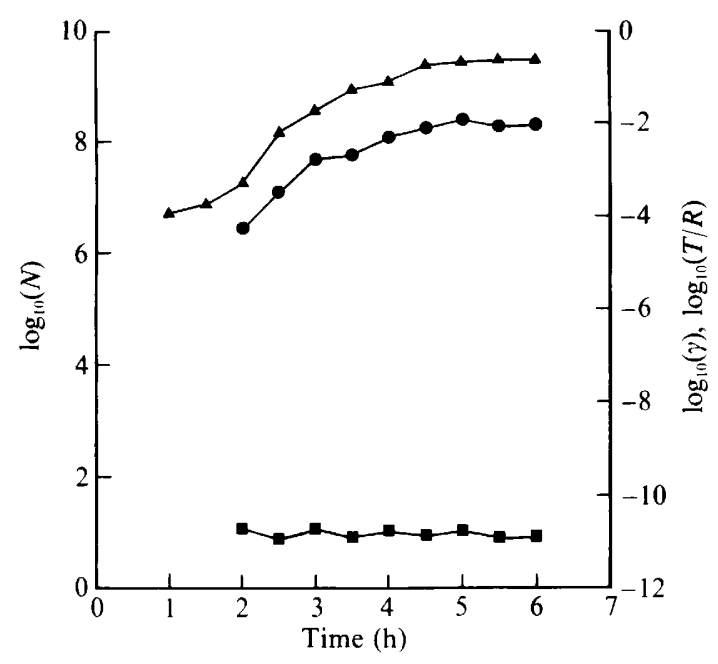

Fig. 1. Experimental data illustrating the change through time in total cell density, $N(\Lambda)$, transconjugant : recipient ratio $(T / R)(O)$ and the estimated rate of plasmid transfer, $\gamma(\boldsymbol{\square})$, using the plasmid R1 in E. coli hosts. The population growth rate $\psi$ used to calculate $\gamma$ was $2 \cdot 11 \mathrm{~h}^{-1}$. The $T / D$ ratio (not shown) was very similar to the $T / R$ curve.

\section{Some real plasmid transfer data}

The basic model predicts that our estimate of the plasmid transfer rate is insensitive to factors such as donor: recipient ratios and initial or final cell density. We now demonstrate this empirically for batch mating cultures of $E$. coli. These results also illustrate some of the problems of using alternative plasmid fertility estimates, such as $T / R$ and $T / D$.

Kinetics of plasmid transfer. The model predicts that the rate of plasmid transfer, $\gamma$, is independent of when the mating culture is sampled. To test this, we initiated a single mating culture with $1 \times 10^{5}$ cells per ml LB medium at a $1: 1$ donor :recipient ratio. The population densities $D, R$ and $T$ were determined at different times during exponential growth and at stationary phase. The exponential population growth rate, $\psi$, of the mating culture was estimated to be $2 \cdot 11 \mathrm{~h}^{-1}$.

The end-point estimate $\gamma$ was essentially constant throughout the course of the mating experiment, at about $1 \times 10^{-11}$ (Fig. 1). This result illustrates that $\gamma$ is independent of mating time (from start of the mating culture until growth ceases) or total cell density. In contrast, Fig. 1 demonstrates that the fertility estimate $T / R$ varied by two orders of magnitude.

Effect of initial density. Mating cultures (LB) were initiated with different dilutions of the same 1:1 mixture of donor and recipient cells. The estimated rate of plasmid transfer, $\gamma$, was independent of initial cell density (Table $2 a$ : AOV $\mathrm{F}_{(2,12)}=0.415 ; P>0.50$ ).

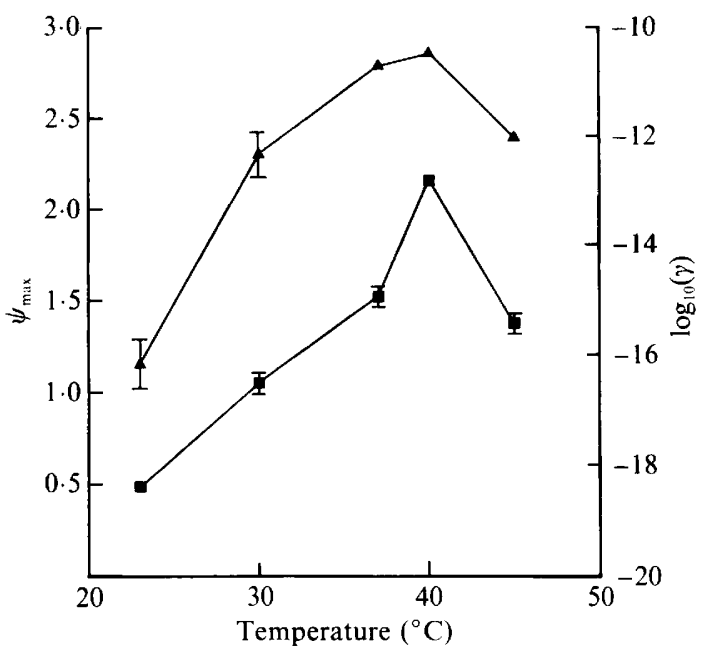

Fig. 2. Effect of temperature on the rate of R1 plasmid transfer in $E$. coli hosts. Liquid (LB) batch mating cultures were inoculated with $1 \times 10^{5}$ cells $\mathrm{ml}^{-1}$ of a 1:1 mating culture of donors and recipients, incubated at temperatures from 23 to $45^{\circ} \mathrm{C}$, and sampled at stationary phase. $\Delta$, Rate of plasmid transfer, $\gamma$ (mean and standard error of five flasks); , estimated exponential phase growth rate, $\psi_{\max }$ (mean and standard error of five flasks).

Effect of donor: recipient ratios. In this experiment we varied the relative frequency of donors and recipients, while maintaining the total initial cell density at about $10^{6}$ cells per $\mathrm{ml} \mathrm{LB}$. As expected, our estimate of the plasmid transfer rate was unaffected by donor:recipient ratio (Table $2 b ; \operatorname{AOV~F}_{(6,28)}=2.239 ; P>0.05$ ). In contrast, the alternative estimates of plasmid fertility, $T / D$ and $T / R$, varied by several orders of magnitude (Table $2 b$ ).

Effect of glucose concentration. We investigated the effect of varying the stationary-phase cell density by using different concentrations of glucose in carbon-limited minimal salt medium. Flasks were inoculated with about $1 \times 10^{5}$ cells $\mathrm{ml}^{-1}$ at a $1: 1$ donor : recipient ratio. The exponential-phase growth rates varied from 0.42 to $0.68 \mathrm{~h}^{-1}$, and the stationary-phase cell densities varied by an order of magnitude. However, the rate of plasmid transfer was independent of glucose concentration (Table $2 c:$ AOV $F_{4,20)}=2 \cdot 193 ; P>0 \cdot 10$ ). Once again, the frequency estimates $T / R$ and $T / D$ varied among treatments.

\section{An application of the end-point method}

One of the advantages of the end-point method is that it allows us to extract the effects on plasmid transfer of environmental factors that also affect the population growth rate. To illustrate this, we investigated the effect of temperature on the rate of plasmid transfer. We 
Table 2. Results of liquid batch culture mating experiments for the plasmid RI in E. coli hosts

We report the calculated value of $\gamma$, and the estimates $T / R$ and $T / D$ for comparison. (a) Initial density. Donors and recipients $(1: 1$ ratio) were mated in $L B$ at different initial densities and sampled at stationary phase. The population growth rate $\psi_{\max }$ was estimated as $2 \cdot 11 \mathrm{~h}^{-1}$. (b) $D / R$ ratios. This ratio was varied while keeping the total initial density constant at about $1 \times 10^{6}$ per ml LB. While the plasmid transfer rate, $\gamma$, was unaffected by changing the ratios, $T / R$ and $T / D$ varied by orders of magnitude. $\psi_{\max }=2 \cdot 11 \mathrm{~h}^{-1}$. (c) Glucose concentration. Flasks containing|minimal salt medium with different glucose concentrations were inoculated with $1 \times 10^{5}$ cells $\mathrm{ml}^{-1} \quad(1: 1$ donor : recipient ratio) and sampled at stationary phase. We report the $\psi_{\max }$ for each glucose concentration and the total cell density, $N$, at stationary phase.

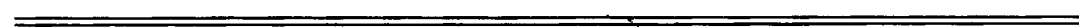

(a) Initial density

\begin{tabular}{cccc}
$\begin{array}{c}\text { Density } \\
\text { (cells ml }{ }^{-1} \text { ) }\end{array}$ & $\gamma$ & $T / R$ & $T / D$ \\
\hline $1 \times 10^{7}$ & $1.7 \times 10^{-12}$ & $1.4 \times 10^{-3}$ & $1.8 \times 10^{-3}$ \\
$1 \times 10^{5}$ & $1.3 \times 10^{-12}$ & $1.2 \times 10^{-3}$ & $1.9 \times 10^{-3}$ \\
$1 \times 10^{3}$ & $1.4 \times 10^{-12}$ & $1.5 \times 10^{-3}$ & $2.8 \times 10^{-3}$ \\
\hline
\end{tabular}

(b) Donor/recipient ratio

\begin{tabular}{lccc} 
Ratio & $\gamma$ & $T / R$ & $T / D$ \\
\hline $1: 1000$ & $4.9 \times 10^{-12}$ & $3.2 \times 10^{-6}$ & $8.2 \times 10^{-3}$ \\
$1: 100$ & $7.2 \times 10^{-12}$ & $4.1 \times 10^{-5}$ & $1.2 \times 10^{-2}$ \\
$1: 10$ & $3.5 \times 10^{-12}$ & $2.4 \times 10^{-4}$ & $7.9 \times 10^{-3}$ \\
$1: 1$ & $1.7 \times 10^{-12}$ & $1.4 \times 10^{-3}$ & $1.8 \times 10^{-3}$ \\
$10: 1$ & $4.0 \times 10^{-12}$ & $3.2 \times 10^{-3}$ & $1.3 \times 10^{-3}$ \\
$100: 1$ & $3.0 \times 10^{-12}$ & $5.7 \times 10^{-3}$ & $7.9 \times 10^{-5}$ \\
$1000: 1$ & $3.0 \times 10^{-12}$ & $5.5 \times 10^{-3}$ & $9.9 \times 10^{-6}$ \\
\hline
\end{tabular}

(c) Glucose concentration

\begin{tabular}{cccccc}
\hline $\begin{array}{c}\text { Glucose } \\
\left(\mu \mathrm{g} \mathrm{ml}^{-1}\right)\end{array}$ & $\psi_{\max }$ & $\gamma$ & $T / R$ & $T / D$ & $N$ \\
\hline 900 & 0.67 & $1.0 \times 10^{-12}$ & $4.9 \times 10^{-4}$ & $5.0 \times 10^{4}$ & $8.0 \times 10^{8}$ \\
600 & 0.65 & $3.3 \times 10^{-13}$ & $1.3 \times 10^{-4}$ & $1.3 \times 10^{4}$ & $5.8 \times 10^{8}$ \\
300 & 0.64 & $4.0 \times 10^{-13}$ & $7.9 \times 10^{-5}$ & $8.4 \times 10^{5}$ & $2.8 \times 10^{8}$ \\
90 & 0.58 & $1.4 \times 10^{-12}$ & $5.4 \times 10^{-5}$ & $3.8 \times 10^{5}$ & $2.7 \times 10^{7}$ \\
30 & 0.42 & $9.4 \times 10^{-13}$ & $2.5 \times 10^{-5}$ & $1.5 \times 10^{5}$ & $1.7 \times 10^{7}$ \\
\hline \hline
\end{tabular}

inoculated flasks containing LB with $1 \times 10^{5}$ cells ml $^{-1}$ at a 1:1 donor: recipient ratio. Although the pattern of change in growth rate and plasmid transfer rate with temperature was similar, the growth rates varied by less than fivefold while the rate of transfer varied by five orders of magnitude over the range of temperatures from 23 to $45^{\circ} \mathrm{C}$ (Fig. 2).

\section{Discussion}

We have presented an experimental protocol for quantifying plasmid transfer based on a single end-point estimate of the donor, recipient and transconjugant densities and the population growth rate. The formula for estimating transfer rates is derived from a mathemat- ical model of the kinetics of cell growth and plasmid transfer under batch culture conditions. The estimate $\gamma$ is an absolute measure of the rate of plasmid transfer and is independent of the kinetics of the mating process.

Our experiments with $E$. coli strains and the plasmid $\mathrm{R} 1$ have shown that $\gamma$ overcomes many of the shortcomings of other estimates of plasmid fertility, such as $T / R$ and $T / D$. Unlike these estimates, $\gamma$ is independent of cell density, donor: recipient ratios and mating time.

We explored the sensitivity of our method to departures from the assumptions underlying the model. Using computer simulations, we investigated complications which do not readily lend themselves to experimental studies, such as transitory derepression and plasmid segregation. Although each of these complications has some effect on our ability to estimate the rate of plasmid 
transfer accurately, our simulation results suggest that the end-point method provides a reasonable estimate under all but the most extreme conditions.

The occurrence of a lag phase has no appreciable influence on the estimate $\gamma$. This result is not surprising, since donor and recipient densities are at their lowest during lag phase and the production of transconjugants is small relative to transconjugant yield during exponential phase. Although high segregation rates resulted in $\gamma$ underestimating the transfer rate, such rates are only likely to be encountered when the cells harbour incompatible plasmids (Novick, 1987) and the effect was only significant when the plasmid transferred at a high rate. The existence of transitory derepression of conjugative pilus synthesis can result in $\gamma$ overestimating the original donor transfer rate. It is difficult to evaluate the potential significance of this result, as there is little data on the duration of transitory derepression.

Growth rate differences are likely to be encountered in mating experiments and the results of our simulations demonstrate that the transfer rate will be overestimated when transconjugants have a growth rate advantage relative to either the donor or recipient population. The degree of overestimation increased for lower plasmid transfer rates.

An analysis of the experimental data presented in Table 2 suggests that we can detect a $70 \%$ difference between the means of two data sets $80 \%$ of the time (for a sample size of 5 and at the 0.05 level of significance) (Sokal \& Rohlf, 1969; p. 247). Our simulation results suggest that, given a wide range of biologically reasonable parameter values, the systematic error associated with our transfer estimate is less than $40 \%$. Given that the degree of experimental error associated with mating experiments is much higher, the systematic errors due to factors such as segregation may be insignificant.

We originally developed the end-point method for studies of plasmid transfer between $E$. coli strains, where there is little cell death and no plasmid transfer during stationary phase (Simonsen, 1990). Therefore, for E. coli, it is convenient to sample mating cultures at stationary phase. However, bacteria such as Pseudomonas and Haemophilus die soon after entering stationary phase, and there may be cases where plasmid transfer continues after growth ceases. In such circumstances, care should be taken to sample prior to the onset of stationary phase.

This method is formally only applicable when measuring the rate of plasmid transfer in liquid habitats. However, many plasmids transfer at a much higher rate in surface habitats than in liquid (Bradley et al., 1980). Although no mathematical model has been developed describing the kinetics of plasmid transfer in surface habitats, our technique may be appropriate under some circumstances. Simonsen (1990) demonstrated an apparent mass-action fit for the kinetics of plasmid transfer on surfaces when cells (micro-colonies) form a confluent surface layer. This result suggests that $\gamma$ can be used as a relative measure of the rate of plasmid transfer in surface mating experiments, provided that the surface cultures are initiated with a high density $\left(>1 \times 10^{6} \mathrm{cells} \mathrm{cm}^{-2}\right)$ of a 1:1 ratio of donors and recipients under conditions where all cells can grow and where the population densities of donors, recipients and transconjugants can be quantified.

There is clearly a need to develop protocols for estimating plasmid transfer rates in natural habitats where surface growth, flow and cell death are important and conditions are far more complicated than life in a test tube. In the meantime, we suggest that however these experiments are undertaken it is critical to report donor, recipient and transconjugant densities and the growth rate of the cells.

This research was supported by the Environmental Protection Agency, the Danish Center for Microbiology, the Canadian Medical Research Council and a National Institute of Health grant GM33782.

\section{References}

ANDERSON, E. S. (1975). Viability of, and transfer from, E. coli K-12 in the human intestine. Nature, London 255, 502-504.

Anderson, R. M. \& MAY, R. M. (1978). Regulation and stability of host-parasite population interactions. I. Regulatory processes. Journal of Animal Ecology 47, 219-247.

BALE, M. J., FRY, J. C. \& DAY, M. J. (1987). Plasmid transfer between strains of Pseudomonas aeruginosa on membrane filters attached to river stones. Journal of General Microbiology 133, 3099-3107.

Bence, J., Blythe, S., Gurney, W., Mass, P. \& Nisbet, R. (1986). SOLVER, an adaptable program template for initial value problem solving. University of Strathclyde, Glasgow, Scotland: Applied Physics Industrial Consultants.

Bradley, D. E., Taylor, D. E. \& Cohen, D. R. (1980). Specification of surface mating systems among conjugative drug resistance plasmids in Escherichia coli K12. Journal of Bacteriology 143, $1466-1470$.

Curtiss, R., ili, Caro, L. G., Allison, D. P. \& Stallions, D. R. (1969). Early stages of conjugation in E. coli. Journal of Bacteriology 100, 1091-1104.

Levin, B. R., Stewart, F. M. \& Rice, V. A. (1979). The kinetics of conjugative plasmid transmission: fit of a simple mass action model. Plasmid 2, 247-260.

LuNDQuIST, P. D. \& LeVIN, B. R. (1986). Transitory derepression and the maintenance of conjugative plasmids. Genetics 113, 483-497.

Miller, J. H. (1972). Experiments in Molecular Genetics. Cold Spring Harbor, NY: Cold Spring Harbor Laboratory.

MONOD, J. (1949). The growth of bacterial cultures. Annual Review of Microbiology 2, 371-394.

Novick, R. P. (1987). Plasmid incompatibility. Microbiological Reviews 51, 381-395.

Sambrook, J., Fritsch, E. F. \& Maniatis, T. (1989). Molecular Cloning : a Laboratory Manual, 2nd edn. Cold Spring Harbor, NY: Cold Spring Harbor Laboratory.

SIMONSEN, L. (1990). Dynamics of plasmid transfer on surfaces. Journal of General Microbiology 136, 1001-1007.

SoKal, R. R. \& RohlF, F. J. (1969). Biometry. San Francisco: W. H. Freeman.

WATANABE, T. (1963). Infective heredity of multiple drug resistance in bacteria. Bacteriological Reviews 27, 87-115.

WILLETTS, N. S. (1974). The kinetics of inhibition of Flac transfer by R100 in E. coli. Molecular and General Genetics 129, 123-130. 